\title{
Separation of contributions from radiative feedbacks to polar amplification on an aquaplanet
}

Langen, Peter Lang; Graversen, Rune Grand; Mauritsen, Thorsten

Published in:

Journal of Climate

DOI:

10.1175/JCLI-D-11-00246.1

Publication date:

2012

Document version

Early version, also known as pre-print

Citation for published version (APA):

Langen, P. L., Graversen, R. G., \& Mauritsen, T. (2012). Separation of contributions from radiative feedbacks to polar amplification on an aquaplanet. Journal of Climate, 25(8), 3010-3024. https://doi.org/10.1175/JCLI-D-1100246.1 


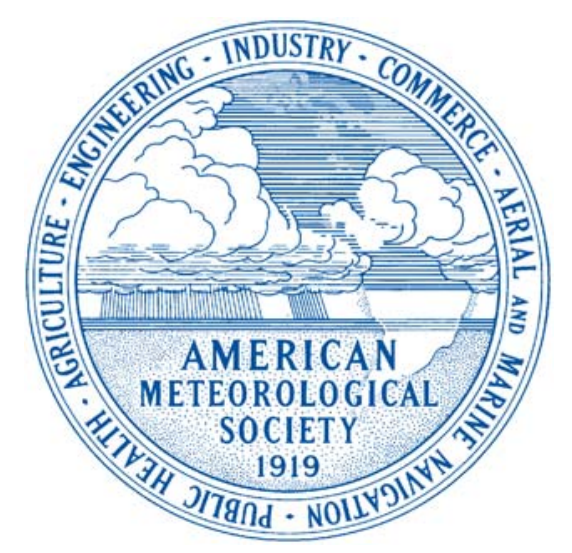

\section{AMERICAN \\ METEOROLOGICAL SOCIETY}

Journal of Climate

\section{EARLY ONLINE RELEASE}

This is a preliminary PDF of the author-produced manuscript that has been peer-reviewed and accepted for publication. Since it is being posted so soon after acceptance, it has not yet been copyedited, formatted, or processed by AMS Publications. This preliminary version of the manuscript may be downloaded, distributed, and cited, but please be aware that there will be visual differences and possibly some content differences between this version and the final published version.

The DOI for this manuscript is doi: 10.1175/JCLI-D-11-00246.1

The final published version of this manuscript will replace the preliminary version at the above DOI once it is available. 


\section{Separation of contributions from radiative feedbacks to polar} amplification on an aquaplanet

\section{Peter L. LANGen *}

Centre for Ice and Climate, Niels Bohr Institute, University of Copenhagen, Copenhagen, Denmark Rune Grand Graversen

Department of Meteorology (MISU), Stockholm Unhersity, Stockholm, Sweden ThORSTEN MAURITSEN

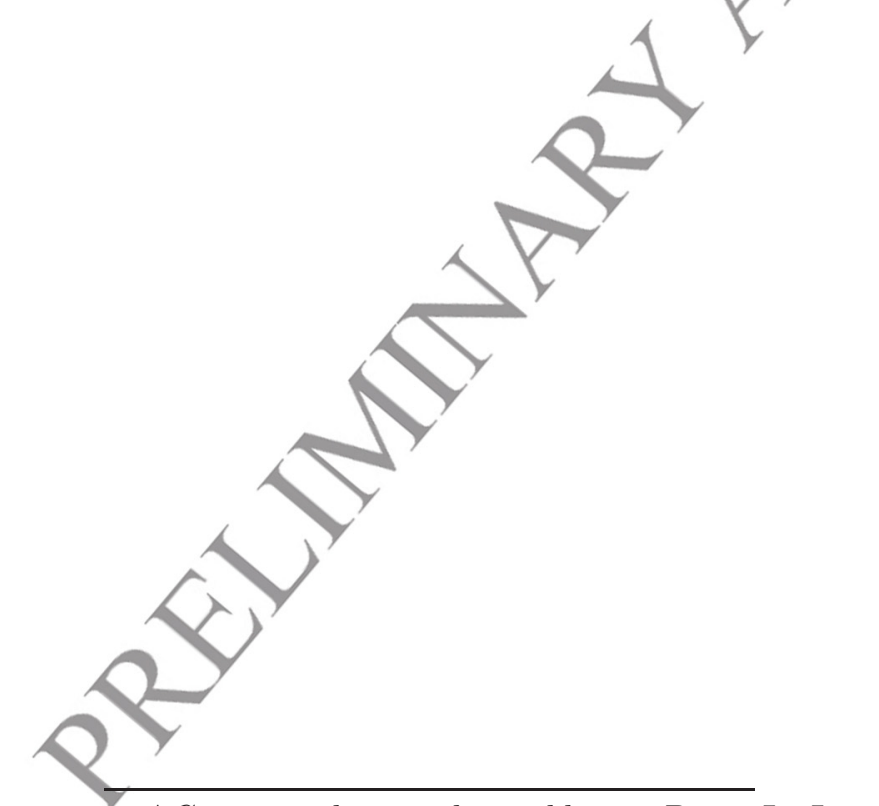

Max Planck Institut für Meteorologie, Hamburg, Germany

* Corresponding author address: Peter L. Langen, Centre for Ice and Climate, Niels Bohr Institute, University of Copenhagen, Juliane Maries Vej 30, DK-2100 Copenhagen O, Denmark.

E-mail: plangen@gfy.ku.dk 
7 When climate is forced by a doubling of $\mathrm{CO}_{2}$, a number of feedback processes are induced, such as changes of water vapor, clouds and surface albedo. Here the $\mathrm{CO}_{2}$ forcing and concomitant feedbacks are studied individually using a general circulation model coupled to an aquaplanet mixed layer ocean. A technique for fixing the radiative effects of moisture and clouds by re-using these variables from $1 \times \mathrm{CO}_{2}$ and $2 \times \mathrm{CO}_{2}$ equilibrium climates in the model's radiation code allows for a detailed decomposition of forcings, feedbacks and responses. The cloud feedback is in this model found to have a weak global average effect and surface albedo feedbacks have been eliminated. As in previous studies, the water vapor feedback is found to approximately double climate sensitivity, but while its radiative effect is strongly amplified at low latitudes, the resulting response displays about the same degree of polar amplification as the full all-feedbacks experiment. In fact, atmospheric energy transports are found to change in a way that yields the same meridional pattern of response as when the water vapor feedback is turned off. We conclude that while the water vapor feedback does not in itself lead to polar amplification by increasing the ratio of high- to low-latitude warming, it does double climate sensitivity both at low and high latitudes. A polar amplification induced by other feedbacks in the system, such as the Planck and lapse rate feedbacks here, is thus strengthened in the sense of increasing the difference in high and low latitude warming. 


\section{Introduction}

The climate system responds by warming or cooling when subjected to external forcing inducing a radiative imbalance at the top-of-the-atmosphere (TOA). The climate change in turn invokes a number of feedback processes which further alter the TOA radiative imbalance and the climate response. A forcing due to an increase of greenhouse gases has its largest radiative effect in the tropical regions (e.g., Hansen et al. 2005), but model experiments reveal that the surface air temperature (SAT) response is largest at polar latitudes, an effect which is referred to as polar amplification (e.g., Manabe and Wetherald 1975; Holland and Bitz 2003). In fact, recent climate change, which is attributed mainly to greenhouse gas forcing, is characterized by a larger temperature change in the Arctic than at lower latitudes (Rigor et al. 2000; Johannessen et al. 2004; Graversen et al. 2008). This high-latitude temperature amplification is believed to be caused by the surface albedo feedback (Manabe and Wetherald 1975; Manabe and Stouffer 1980; Serreze et al. 2009; Screen and Simmonds 2010a,b), changes of the meridional heat transport in both the atmosphere (Alexeev 2003; Graversen 2006; Langen and Alexeev 2007; Zhang et al. 2008; Graversen et al. 2008; Serreze et al. 2009) and the ocean (Polyakov et al. 2010; Spielhagen et al. 2011), and the weak vertical mixing in the Arctic lower troposphere (Manabe and Wetherald 1975). Also increasing amounts of black carbon on snow may be a contributing factor to the recent Arctic temperature increase (Shindell and Faluvegi 2009).

Feedback mechanisms associated with, for instance, changes of water vapor, lapse rate, surface albedo, and clouds modify the climate response. The water vapor feedback is positive and believed to approximately double the SAT response (e.g., Held and Soden 2000; Soden et al. 2008). The atmospheric lapse rate is changed during global warming and at low latitudes excess energy at the surface is transported by convection to higher altitudes from where it is efficiently radiated to space. The opposite is the case at high latitudes where convection is suppressed by the stably stratified atmosphere. As a result, the lapse rate feedback is likely negative at low latitudes and positive at high latitudes, but is believed to 
be negative in global average (Soden and Held 2006). The surface albedo feedback is positive and has a small global but significant high-latitude effect (e.g., Winton 2006). Clouds yield both a greenhouse effect warming the Earth's surface, and an albedo effect, which tends to cool climate. In today's climate, the total cloud radiative effect is to cool the planet (e.g., Schneider 1972; Ramanathan et al. 1989), but when it comes to the cloud feedback, models tend to disagree. In most state-of-the-art models, clouds provide a positive feedback during the $\mathrm{A} 1 \mathrm{~B}$ emission scenario corresponding to approximately a $\mathrm{CO}_{2}$ doubling over the 21st century (Soden et al. 2008). However, the spread among the models is large and some models show a weak or even negative cloud feedback. Other processes within the climate system, which constitute only weak feedbacks may still be important for the climate response. For instance, a change of the meridional heat transport may induce large regional effects, although its impact on the global TOA radiative balance is rather small.

A breakdown of the SAT response into the part directly related to the forcing and the parts resulting from each of the feedbacks is a difficult task, since the involved processes operate simultaneously and are mutually dependent. A warming due to the water vapor feedback, for instance, will cause further ice melt and warming due to the surface albedo feedback. As a further complication, the feedbacks mask each other. The radiative effect of water vapor changes is modified by the presence of clouds, and the radiative effect of cloud changes is dependent on the albedo of the surface below the clouds. Nevertheless, a decomposition of the feedbacks is valuable as it provides detailed insight into how the climate system reacts to forcings. It may, for example, shed further light on the processes important for the Arctic temperature amplification.

Different approaches have been taken in order to obtain a decomposition of the feedbacks invoked by a radiative forcing. The cloud feedback has been studied by fixing the sea surface temperatures (SST) at two different levels in general circulation models (Cess et al., 1990). Here, the cloud feedback was estimated from the change of the cloud forcing calculated from the difference between TOA net radiation for cloudy and clear sky. It has, however, been 
noted that cloud forcing may change even if cloud properties are unchanged between the two SST levels (e.g., Zhang et al. 1994; Soden et al. 2008). A part of the cloud forcing change is thus due only to differences in cloud masking of the other feedbacks - especially the water vapor feedback - at the two SST levels.

An off-line approach, where the feedback processes are examined individually using a single column energy balance model (Hansen et al. 1994), or the full radiation codes from climate models (Wetherald and Manabe 1988; Colman 2003), has been used more widely to separate the feedbacks. In this so-called partial radiative perturbation (PRP) approach, the fields associated with a given feedback are set at two levels, corresponding to the control and perturbed climate, in the radiation code while keeping all other fields at the control state. The difference in radiation between the two settings provides the radiative effect associated with the feedback in question. In the PRP approach, it is important that correlation effects are taken into account (Colman and McAvaney 1997; Soden et al. 2008). If, for instance, humidity and clouds are related, clouds will partly mask or amplify the greenhouse effect of humidity. A de-correlation of the two in the standard off-line method outlined above will thus in itself contribute spuriously to the radiative effect of water vapor. Another diagnostic method based on radiative kernels has been undertaken to circumvent the correlation problems. In this method, mean perturbations rather than differences between temporally varying states are used to estimate the radiative effect associated with a given feedback (Soden and Held 2006; Soden et al. 2008).

Dufresne and Bony (2008) illustrated elegantly how diagnosed feedback factors may be inverted to give a decomposition of the surface warming into contributions from the individual feedbacks by assuming linearity. A drawback of this inverse calculation is that the feedback factors need to be known and that it is not straightforward to determine spatial patterns in the decomposition. A locking of feedbacks on-line in the climate model as performed in this study provides a more direct feedback decomposition. One advantage is that the response to the feedbacks in terms of, for example, the regional SAT change can be 
studied in detail. A disadvantage is that the on-line locking of the feedbacks is technically demanding and will likely become even more so as the complexity of models increases. One thing to consider is that also here the de-correlation effects have to be taken into account. Such an on-line approach has been taken in order to study the feedbacks of clouds (Wetherald and Manabe 1988), water vapor (Hall and Manabe 1999), and surface albedo (Hall 2004; Bitz 2008; Graversen and Wang 2009). In these studies, doubling $\mathrm{CO}_{2}$ experiments with free feedbacks are compared to similar experiments with the feedback in question suppressed. In this design, however, the SAT response cannot be solely attributed to the feedback in question since leaving this feedback free will in itself invoke other feedbacks. In the above mentioned water vapor experiment, for example, the SAT response from a doubling of $\mathrm{CO}_{2}$ was 3.2 times larger when the water vapor feedback was included than when it was suppressed. This high value was partly attributed to enhancement of other feedbacks such as those of surface albedo and clouds. These feedbacks were further activated when the water vapor induced warming was included (Hall and Manabe 1999).

Here we use the on-line method but take a more comprehensive approach than the above studies by locking both the water vapor and the cloud fields simultaneously. In addition, we suppress the surface albedo feedback by using an aquaplanet model with no sea ice. Thereby the responses due to water vapor and cloud feedbacks can be effectively separated from each other and from the surface albedo feedback. This separation allows for a more detailed attribution of the meridional structure of the temperature response in terms of forcing and feedback processes.

\section{Experimental configuration}

The National Center for Atmospheric Research CAM3 model (Collins et al. 2006) is employed in a configuration that has been modified somewhat from its original distributed form. In addition to the specification of cloud and moisture variables in the radiation code as 
described below, we have made a number of further simplifications to the model configuration in order to ease the interpretation and clearer illustrate the effects; we have thus i) removed the continents leaving a flat, water covered aquaplanet-Earth, ii) removed sea ice such that even sub-freezing points are treated as open ocean, iii) fixed the albedo in all points to 0.15 at all times, iv) symmetrized all input files such as aerosol and ozone between the hemispheres and v) set the eccentricity of Earth's orbit to zero in order to leave the solar forcing symmetric between the hemispheres while still retaining the seasonal cycle. In addition, when the model is run in slab ocean mode, a smooth and hemispherically symmetric ocean heat transport convergence ("q-flux") is used to transport $1 \mathrm{PW}\left(10^{15} \mathrm{~W}\right)$ from low to high latitudes and a mixed layer depth of $50 \mathrm{~m}$ is used in all points at all times. The choice of ocean heat transport strength will influence the equilibrium climate obtained with the model, and with the round-number choice of $1 \mathrm{PW}$ the model exhibits a reasonable annual mean climate. The strength is kept constant across all experiments and thus provides no feedback to the system. The model is run with a Eulerian spectral dynamical core with a horizontal resolution of T42, which corresponds to about $2.8^{\circ} \times 2.8^{\circ}$, and 26 hybrid-sigma levels in the vertical. The solar constant is set to $1365 \mathrm{~W} \mathrm{~m}^{-2}$ and the control $\mathrm{CO}_{2}$ concentration $\left(1 \times \mathrm{CO}_{2}\right.$ henceforth $)$ is $355 \mathrm{ppm}$. In spite of these simplifying changes, the model is still a full atmospheric GCM with all physics and dynamics included as in the distributed version of the CAM3 (Collins et al. 2006). This study may thus be seen partly as an example of the feedback-locking technique applied in a model with a broad user-base, and the authors are pleased to share the code necessary to set up similar experiments.

Running the model forward with the above changes and with clouds and water vapor calculated interactively yields a control climate as illustrated by the annual mean zonally averaged surface temperature curve displayed in Figure 1 a. This climate is taken as an average over 30 years of integration after a 20 year spinup period. Doubling of the atmospheric $\mathrm{CO}_{2}$ concentration to $710 \mathrm{ppm}\left(2 \times \mathrm{CO}_{2}\right)$ results in the annual and zonal average climate also shown in Figure 1 a. The surface temperature change as a result of the $\mathrm{CO}_{2}$ change is 
shown by the curve marked $d T$ (right axis). The global average temperature change is 1.65 $\mathrm{K}$, as compared to the climate sensitivity of the CAM3 coupled to a slab ocean model in the standard configuration with continents and sea ice of $2.47 \mathrm{~K}$ (Kiehl et al. 2006). The response shows a clear polar amplified pattern with equatorial warming of less than $1.4 \mathrm{~K}$ and polar warming of up to $2.2 \mathrm{~K}$. It is this polar amplification we aim to dissect in terms of direct effects of the $\mathrm{CO}_{2}$ forcing and the feedback effects from clouds and water vapor.

\section{a. Deactivating cloud and water vapor feedbacks}

To deactivate water vapor and cloud feedbacks, we read out and re-use the water vapor and cloud fields from the $1 \times \mathrm{CO}_{2}$ and $2 \times \mathrm{CO}_{2}$ experiments. We do this by reading out hourly values for the three dimensional fields of water vapor and five cloud parameters, namely cloud fraction, cloud liquid water, cloud ice and effective radii of liquid droplets and ice crystals. The water vapor and the cloud feedbacks are then locked by reading these fields back into the model and letting them substitute the on-line produced fields in the model's radiation code. It is important to stress that we are not replacing the water vapor and clouds in the rest of the code and hydrological processes such as evaporation, latent heat transport and precipitation are thus performed with the model's interactively calculated fields.

In Figure $1 \mathrm{~b}$ and $\mathrm{c}$ are shown the annual and zonal mean changes in water vapor and cloud fraction, respectively. The water vapor mixing ratio increases everywhere but most strongly near the surface and at low latitudes. Cloud fraction is more complex and displays an upward shift of the equatorial deep convective cloud tops, a decrease in mid-latitude cloudiness and increases in high-latitude cloudiness. We only show the mean changes but as demonstrated in previous studies (e.g., Schneider et al. 1999; Vavrus 2004; Langen and Caballero 2007) the variability of cloud and moisture fields are vital for reproducing the radiation fields properly. It is for this reason that we perform the read-out and read-in at one-hourly resolution.

Throughout the study we will be discussing experiments in which cloud variables and 
moisture variables are combined in various ways from their $1 \times \mathrm{CO}_{2}$ and $2 \times \mathrm{CO}_{2}$ distributions. It is worth noting that the moisture field, for instance, from the $2 \times \mathrm{CO}_{2}$ climate comprises the full change, which includes the change that arises due to the direct warming from $\mathrm{CO}_{2}$ along with the changes that arise due to the water vapor and cloud feedback induced warmings. If, for example, the climate change induces a cloud change, which induces a temperature change which, in turn, induces a moisture change, this moisture change will be taken as part of the water vapor feedback even though it would not have occurred unless the clouds had changed. In some sense, the feedbacks are thus aliased somewhat into each other but this is also the case when performing the feedback calculations using the off-line approach (e.g., Wetherald and Manabe 1988; Colman 2003). Especially the water vapor feedback is expected to enhance other feedbacks considerably, since it is responsible for around half the response associated with a $\mathrm{CO}_{2}$ change. We do, however, go one step further compared to other on-line feedback studies in that we are able to lock other feedbacks than just the one we are studying. When we, for instance, turn on the water vapor feedback by using moisture from the $2 \times \mathrm{CO}_{2}$ climate, we only get the water vapor contribution to the radiation change and not an associated change in clouds or surface albedo.

A related concern is whether it is reasonable to combine cloud, water vapor and dynamical fields that do not correspond to the same synoptic situation. We run the dynamical core and the hydrologic cycle forward while specifying clouds and moisture from files and, as we discuss next, we even take care to shift the cloud and moisture fields in time relative to each other. This clearly has the potential to create some rather unphysical states where the model, for example, encounters clear skies and sunshine in the middle of a storm. This is, however, not deemed problematic for the present study since i) water vapor is only specified in the radiation code, so the dynamical feedbacks associated with heat and moisture advection and latent heat release are retained and thus continue to support cyclogenesis as in the 'free' experiments, and ii) as will be shown, the effects nevertheless turn out to combine linearly such that the individual effects of changing $\mathrm{CO}_{2}$, clouds and moisture sum up to the effect 
seen when all are changed simultaneously.

\section{b. Specified SST experiments}

Before proceeding with the slab ocean experiments with locked clouds and water vapor, it is illustrative and important to evaluate the radiative effects of the $\mathrm{CO}_{2}$-doubling, the cloud change and the water vapor change. To do this, we first produced symmetrized versions of the SST climatologies from the $1 \times \mathrm{CO}_{2}$ and $2 \times \mathrm{CO}_{2}$ experiments (with the symmetrization shifted six months between the hemispheres). Then the model was run with SSTs specified to these climatologies thus producing cloud and moisture data sets corresponding to each. These were then re-used in new specified SST, or so-called data ocean model (dom), runs where $1 \times \mathrm{CO}_{2}$ and $2 \times \mathrm{CO}_{2}$ cloud and moisture fields were combined as summarized in Table 1 . The naming convention is such that if $\mathrm{CO} 2$ enters in the name, then $\mathrm{CO}_{2}$ has been doubled in the radiation code, if $\mathrm{WV}$ enters in the name, then water vapor has been taken from the $2 \times \mathrm{CO}_{2}$ experiment (elsewise from the $1 \times \mathrm{CO}_{2}$ experiment), and if CLD enters in the name, then cloud variables have been taken from the $2 \times \mathrm{CO}_{2}$ experiment (elsewise from the $1 \times \mathrm{CO}_{2}$ experiment). If the word "shift" is appended to the name, it indicates that, as explained below, the water vapor and cloud fields have been shifted by one year relative to each other. As an example, the experiment domWV\&CLD has $1 \times \mathrm{CO}_{2}$ in the atmosphere, while water vapor and clouds have been taken from the $2 \times \mathrm{CO}_{2}$ experiment and have not been shifted relative to each other. Taking the differences between the TOA radiation budgets in these experiments allows an assessment of the fixed SST radiative forcing (as advocated by Alexeev 2003; Shine et al. 2003; Hansen et al. 2005) due to the $\mathrm{CO}_{2}$ change and the feedbacks due to clouds and moisture. It has been demonstrated (e.g., Gregory and Webb 2008; Andrews and Forster 2008) that the fixed SST forcing includes indirect contributions from both stratospheric and tropospheric adjustment, such that it better represents the imbalance that the surface temperatures must adjust to.

Before doing this, however, we need to consider and discount the effects that arise be- 
cause the cloud and moisture fields are correlated in time in the runs that produce them. This correlation could be retained if moisture and cloud fields were always taken from the same climate, i.e., $1 \times \mathrm{CO}_{2}$ or $2 \times \mathrm{CO}_{2}$, but since the idea is to study the effects of the two separately, this is not possible. We need to be able to take moisture and clouds from different runs and we are faced with the problem of losing the correlation between the fields. The effect of this is seen by comparing the TOA radiation budgets in runs in which cloud and moisture fields are simultaneous and in runs where they have been shifted relative to each other by one year. In Figure 2 a, the solid line is the difference in TOA radiation calculated as domCTRLshift-domCTRL and the dashed line is domWV\&CLDshift-domWV\&CLD. In both cases the de-correlation leads to a warming tendency of about $1 \mathrm{~W} \mathrm{~m}^{-2}$ globally. This means, for instance, that comparing a run where clouds are replaced by their $2 \times \mathrm{CO}_{2}$ counterpart, to a control run where clouds and moisture are correlated, would show both the part of the radiation change due to the de-correlation effect and the part due to the cloud change. The solution is to also de-correlate the water vapor and cloud fields in the control run by shifting them relative to each other, and instead of having correlations in some experiments and not in others, we thereby make sure that the correlation is excluded in all experiments. Hereby the correlation effect is effectively excluded from the feedback estimations. As a check on whether this gives valid results, Figure $2 \mathrm{~b}$ shows the radiative effect of changing cloud and moisture fields from their $1 \times \mathrm{CO}_{2}$ to their $2 \times \mathrm{CO}_{2}$ climatologies both when they have been shifted (solid, domWV\&CLDshift-domCTRLshift) and when they have not been shifted (dashed, domWV\&CLD-domCTRL). The fact that the two curves are almost identical confirms that removing the correlation effect from both the changed experiment and the control leads to the correct result while minimizing the correlation bias.

\section{c. Slab ocean experiments}

After using the data ocean experiments to determine the radiative effects associated with the individual changes, the slab ocean model is used to examine the climate response to these 
effects. The same slab ocean configuration is used as was done to generate the $1 \times \mathrm{CO}_{2}$ and $2 \times \mathrm{CO}_{2}$ climates with interactive clouds, with the exception that cloud and moisture fields now are specified. As demonstrated previously, it is important to remove the correlation effect from the experiments and in all the slab ocean experiments this is done as standard. We therefore exclude the "shift" from the naming of slab ocean experiments, and the experiment CTRL, for example, thus has $1 \times \mathrm{CO}_{2}$ concentration in the atmosphere and uses both clouds (five variables) and water vapor from the $1 \times \mathrm{CO}_{2}$ experiment which have been shifted 1 year relative to each other. Apart from the exclusion of the "shift", the naming is the same as for the data ocean experiments and a total of eight different cases were run as outlined in the lower half of Table 1: CTRL (corresponding to a control with specified fields), CLD, WV, WV\&CLD, CO2 (corresponding to a no-feedbacks $2 \times \mathrm{CO}_{2}$ experiment), CO2\&CLD, CO2\&WV and CO2\&WV\&CLD (corresponding to an all-feedbacks experiment).

The experiments have all been run for 50 years and in the following, all averages are taken over the last 30 years. As expected from the symmetric configuration, the results display a large degree of symmetry between the hemispheres. To ease readability we have thus chosen to show all results as averaged and symmetrized between the hemispheres.

\section{Results}

In Figure 3 a the dashed line shows the fixed SST radiative forcing due to doubling $\mathrm{CO}_{2}$ calculated as domCO2shift-domCTRLshift. This forcing has a global average of $3.4 \mathrm{~W} \mathrm{~m}^{-2}$ and displays a strengthening at low latitudes. In comparison, the radiative effect of changing the water vapor is shown by the solid curve (domWV-domCTRLshift). This feedback has a global average of $3.5 \mathrm{~W} \mathrm{~m}^{-2}$ with a stronger equatorial focus. The cloud feedback (domCLD-domCTRLshift), shown in Figure $3 \mathrm{~b}$, displays large meridional differences with cooling tendencies at low and high latitudes and warming tendencies at mid-latitudes. Interpreting this pattern is rather complicated since, as demonstrated by Langen and Caballero 
(2007), it depends on both the mean change and the change in the variability and has both short- and longwave components. Its global mean, however, is only $0.02 \mathrm{~W} \mathrm{~m}^{-2}$ and, as will be shown next, the surface temperature response to the cloud change is much smaller than that to the water vapor and $\mathrm{CO}_{2}$ changes.

\section{a. Decomposition of the warming}

Figure 4 a displays the individual surface temperature responses in the slab ocean experiments to the $\mathrm{CO}_{2}$ change (dashed, CO2-CTRL), the water vapor change (solid, WV-CTRL) and the cloud change (dotted, CLD-CTRL). The two former have quite similar expressions with global averages of about $0.8 \mathrm{~K}$ and a polar amplified shape while the response to the cloud change is weaker with a global average of only $0.07 \mathrm{~K}$.

In panel $\mathrm{b}$ of Figure 4 is shown the surface temperature response in the case of including cloud, water vapor and $\mathrm{CO}_{2}$ effects (solid, $\left.\mathrm{CO} 2 \& W V \& C L D-C T R L\right)$ along with the sum of the curves corresponding to the individual effects (dashed). The similarity between these two curves illustrates that the model climate responds approximately linearly to a combination of the effects; not just in terms of global means but also in terms of the spatial patterns. This is useful, since it allows us to decompose the resulting response into the individual contributions. As a final verification of the methodology, we show in the same panel the change in the "free" $1 \times \mathrm{CO}_{2}$ and $2 \times \mathrm{CO}_{2}$ experiments (dotted). The fact that this curve lines up with the others, indicates that our fixing and decomposition of effects is a sensible approach to understanding the "free" experiment.

It is also interesting to examine the effect of the water vapor and cloud feedbacks in $1 \times \mathrm{CO}_{2}$ and $2 \times \mathrm{CO}_{2}$ background climates. Figure 5 shows this difference for water vapor (panel a) and clouds (panel b), respectively: the solid curve is the effect of changing to $2 \times \mathrm{CO}_{2}$ water vapor (clouds) in a $1 \times \mathrm{CO}_{2}$ climate (WV-CTRL) and the dashed shows the same using $1 \times \mathrm{CO}_{2}$ water vapor (clouds) in a $2 \times \mathrm{CO}_{2}$ climate (CO2\&WV\&CLD-CO2\&CLD). In both cases, the two curves are very similar underlining the linearity of the response. The moisture 
effect is, however, generally slightly weaker in the warm background climate consistent with the same water vapor increase having a weaker radiative effect in an optically thicker $2 \times \mathrm{CO}_{2}$ atmosphere. The difference in the cloud effects has a less obvious interpretation.

Figure 6 shows the annual mean, zonal average atmospheric temperature response for the individual forcings and feedbacks along with their collective effect, their sum and the response in the "free" experiment. In comparison to those of water vapor and $\mathrm{CO}_{2}$, the effect of the cloud feedback is seen to be small near the surface. It displays somewhat larger but still comparatively weak response in the mid- to upper-troposphere. The water vapor and $\mathrm{CO}_{2}$ effects yield tropospheric warming that is strongest near the surface at high latitudes and near the tropopause at low latitudes. These features are typical in warming experiments driven by either greenhouse gas or shortwave effects (e.g., Cubasch et al. 1997) and arise due to the different stratifications at low and high latitudes. The stratospheric cooling in the $\mathrm{CO}_{2}$ experiment is also typical and due to the increased emissivity, an effect which is less pronounced in the WV experiment where mainly tropospheric emissivity is increased by increasing water vapor.

The similarity of panels d and e in Figure 6 demonstrates again that the linear decomposition into the contributions from $\mathrm{CLD}, \mathrm{WV}$ and $\mathrm{CO}_{2}$ is valid and their similarity with panel $\mathrm{f}$ demonstrates that the fixed-fields experiments provide a sensible way of analyzing the free-fields response. It is worth noting that the maximum warming at high latitudes occurs at about $700 \mathrm{hPa}$ in all three panels and not at the very surface. Moreover, the contributions to this warming from panels a-c show that in these experiments, the elevated warming arises due to the changes in clouds, while both $\mathrm{WV}$ and $\mathrm{CO}_{2}$ effects yield a surface amplified warming.

Returning to Figure $4 \mathrm{~b}$, a closer look reveals that the sum of effects (dashed) ceases to closely follow the two other curves (All effects: solid and Free feedback exp: dotted) at mid-to-high latitudes. Here, the linearity of the response seems less perfect and at midlatitudes the sum of effects underestimates the actual response and poleward of about $70^{\circ}$ 
it overestimates it. Instead of combining all three effects as in Figure $4 \mathrm{~b}$, the three possible pairs of effects have also been considered (not shown). This reveals that the non-linearity is seen only in the two combinations including the CLD change. Conversely, the linearity holds at all latitudes when only WV and $\mathrm{CO}_{2}$ effects are considered and we will focus on these two in the following.

\section{b. Water vapor feedback and heat transport contributions}

Comparing the meridional profiles of the radiative effects of $\mathrm{WV}$ and $\mathrm{CO}_{2}$ in Figure 3 a and those of the associated surface temperature responses in Figure 4 a, it is remarkable that while the radiative effects are quite different, the responses are fairly similar. Apparently there must be an adjustment of the meridional heat transport allowing the climate to equilibrate with this temperature response. In Figure $7 \mathrm{a}-\mathrm{c}$ is shown the response in northward atmospheric energy transport in the WV and $\mathrm{CO}_{2}$ experiments and its decomposition into dry static and latent energy components. In panels d-f is shown for completeness the change in the experiment with both $\mathrm{WV}$ and $\mathrm{CO}_{2}$ changed (solid) compared to the sum of the responses in the WV and $\mathrm{CO}_{2}$ experiments (dashed). As has been found in the previous results, linearity also applies here.

In the WV experiment (black solid lines in Figure $7 \mathrm{a}-\mathrm{c}$ ), the changes in the dry static and latent energy transports show latitudinal structures similar to those of the background climate (grey lines, right axis), hereby increasing the transport and retaining the positions of relative minima and maxima. In the $\mathrm{CO}_{2}$ experiment (black dashed lines), on the other hand, the change in mid-latitude latent heat release is shifted poleward and coincides with a decrease in dry static energy transport such that outside the tropics, there is a nearcancellation of the two components. In an attempt to diagnose the reason for the difference in the mid-latitude dry static energy transport response in the $\mathrm{WV}$ and $\mathrm{CO}_{2}$ experiments

(Figure $7 \mathrm{~b}$ ), we will view the sensible heat component as a result of transient eddies diffusing a meridional temperature gradient. In this picture, the transport is proportional to the 
gradient and the diffusivity given by the eddy kinetic energy,

$$
H \sim\left(-\frac{d T}{d y}\right) \cdot \mathrm{EKE}
$$

where $\sim$ denotes positive proportionality and EKE is the transient eddy kinetic energy given by $\overline{u^{\prime 2}+v^{\prime 2}} / 2$. In a dry dynamic framework, we may expect the EKE to be proportional to the Eady growth rate,

$$
\sigma_{B I}=0.31 f \frac{\left|\frac{d V}{d z}\right|}{N}
$$

where $N=\sqrt{g d \ln \theta / d z}$ is the Brunt-Väisälä frequency characterizing the dry static stability, $f$ is the Coriolis parameter and the numerator is the vertical wind shear (Hoskins and Valdes 1990). If we neglect variations in $f$ and $N$ and only consider the vertical shear of the zonal wind, then the thermal wind relates the Eady growth rate to the meridional temperature gradient and the transport is

$$
H \sim\left(-\frac{d T}{d y}\right)\left(-\frac{d T}{d y}\right)=\left(\frac{d T}{d y}\right)^{2}
$$

where the constant of proportionality is still positive. This can be seen as a highly simplified version of the eddy heat flux parameterization by Stone and Yao (1990). A change in the meridional temperature gradient, $\Delta(d T / d y)$, will lead to the relative change in transport

$$
\frac{\Delta H}{H}=2 \frac{\Delta \frac{d T}{d y}}{\frac{d T}{d y}},
$$

and a $1 \%$ increase in temperature gradient will lead to a $2 \%$ increase in eddy heat transport. If we consider the meridional gradient of the vertically averaged lower-tropospheric (900$500 \mathrm{hPa}$ ) temperature in the WV experiment (Figure $8 \mathrm{c}$, solid line) we see a decrease in this gradient in excess of $2 \%$ poleward of $40^{\circ}$. Our simple parameterization is thus unable to account for the increased mid-latitude transport in the WV experiment. The Eady growth rate (also averaged 900-500 hPa, Figure 8 a) has decreased in the entire range in accordance with the decreased temperature gradient, but the change is modest at $70^{\circ}$, where the temperature gradient change is large. Inspection of Figure $6 \mathrm{~b}$ shows that at 
polar latitudes there is a near-surface warming, which apparently counters the temperature gradient effect on the growth rate by decreasing static stability. The decreased temperature gradient and Eady growth rate is not mirrored in the EKE (Figure 8 b) which increases over much of the mid- to high latitudes. We speculate that the stronger mid-latitude latent heat release in the WV experiment relative to the $\mathrm{CO}_{2}$ experiment (Figures $7 \mathrm{c}$ and $9 \mathrm{~d}$ ) can reinforce the eddies relative to the prediction of the dry dynamic Eady growth rate (e.g., Emanuel et al. 1987).

Figure $9 \mathrm{~b}$ and c shows the responses in the zonal mean meridional streamfunction in the $\mathrm{WV}$ and $\mathrm{CO}_{2}$ experiments relative to the control (shown in panel a). These responses are fundamentally different: The response to the strong local low-latitude water vapor feedback is an upward shift of the maximum of the Hadley circulation, while that to the $\mathrm{CO}_{2}$ forcing is more of a weakening and a broadening. Comparing the heating rate due to condensation in the $\mathrm{WV}$ and the $\mathrm{CO}_{2}$ experiments (panel d) shows the deeper convective heating in the WV experiment and a larger low-level and mid-latitude heating. The latter difference is due to a slight poleward shift of the mid-latitude maximum latent heat release accompanying the widening of the circulation in the $\mathrm{CO}_{2}$ experiment. This poleward shift also shows up clearly in Figure $7 \mathrm{c}$, where the peak mid-latitude increase in latent heat transport is shifted $10-15^{\circ}$ poleward relative to that of the $\mathrm{WV}$ experiment. It is this difference in condensation heating that we suspect leads to the difference in dry static energy transport.

The response of the heat transport components may thus tentatively be understood as follows: The circulation responds to the strong low-latitude energy input in the WV experiment (Figure 3 a) by deepening and intensifying the background features of the flow and increasing the net transport (Figure 7 a) by retaining the relative positions of minima and maxima in the latent and dry static components (Figure $7 \mathrm{~b}$ and $\mathrm{c}$ ). In response to the $\mathrm{CO}_{2}$ forcing (Figure $3 \mathrm{a}$ ), however, the low-latitude circulation widens (Figure $9 \mathrm{c}$ ), the midlatitude latent heating shifts poleward (Figure $7 \mathrm{c}$ ) and the structure of the dry static energy transport (Figure $7 \mathrm{~b}$ ) is altered in a way that allows the components to approximately cancel 
(Figure 7 a).

\section{Discussion}

Table 2 shows a simplified representation of the results of the WV and CO2 experiments, omitting those from the CLD experiment which shows only very small response. It gives the forcing due to the $\mathrm{CO}_{2}$ changes and the feedback due to WV in global average, in lowlatitude $\left(0-30^{\circ}\right)$ average and mid- to high-latitude $\left(30-90^{\circ}\right)$ average. The same global average effect of $\sim 3.5 \mathrm{~W} \mathrm{~m}^{-2}$ is found due to $\mathrm{WV}$ and $\mathrm{CO}_{2}$ but the former has a considerably larger low-latitude value and smaller high-latitude value. When the change in meridional energy transport is converted to an area-averaged energy input, insignificant changes of $\pm 0.1 \mathrm{~W}$ $\mathrm{m}^{-2}$ are found in the $\mathrm{CO} 2$ experiment, while changes of $\mp 0.5 \mathrm{~W} \mathrm{~m}^{-2}$ are found in the $\mathrm{WV}$ experiment. When the effects of forcing or feedback and energy transports are added, the total energy input to the boxes are equal in the two experiments and this is mirrored in the similar temperature responses (numbers in italic). In this simple picture, the meridional atmospheric energy transport adjusts exactly such as to counter the differences in energy input to produce the same temperature response. The conclusion is thus that in global average, the forcing due to $\mathrm{CO}_{2}$ is doubled by the water vapor feedback, and while this is not the case regionally, the atmospheric energy transport seems to even out the differences and ensure that it still holds. This result may be both fortuitous and model dependent, but is nevertheless compatible with earlier findings arguing that the climate system has a certain pattern of response which depends little on the geographical distribution of the radiative forcing but more on the internal feedbacks (e.g., Manabe and Wetherald 1980; Boer and Yu 2003; Hansen et al. 2005; Langen and Alexeev 2007). The mechanism responsible for this is, however, still unclear: The results of Boer and Yu (2003) and the present study indicate that the heat transport tends to react to offset imbalances produced by other feedbacks, while Langen and Alexeev (2007) propose that it is the sensitivity of the heat transport feedback 
itself which is responsible.

We will now use the information in Table 2 to estimate not only the global feedback parameters but also low- and high-latitude values thereof. Knowing the forcing, $F_{\mathrm{CO} 2}$, due to the $\mathrm{CO}_{2}$ alone and the temperature response in the $\mathrm{CO} 2$ experiment, where surface albedo, water vapor and cloud properties are fixed, we may calculate the total feedback due to temperature and heat transport changes as

$$
\lambda_{T}=-\frac{F_{C O 2}}{\Delta T_{C O 2}},
$$

where all quantities can be thought of as triplets, containing global, low- and high- latitude values. Values are given in Table 3. The small heat transport change in the CO2 experiment is taken as part of the temperature feedback, $\lambda_{T}$, which is the sum of the Planck and lapse rate feedbacks $\lambda_{T}=\lambda_{0}+\lambda_{L R}$. If we can estimate the former, we can calculate the latter from $\lambda_{T}$. We take the approach of Wetherald and Manabe (1988) to estimate the Planck feedback, namely by determining an effective atmospheric emissivity that yields the TOA flux from the surface air temperature, $T_{S A}$, as

$$
F_{L W, t o a}=\epsilon \sigma T_{S A}^{4},
$$

where $\sigma$ is the Stefan-Boltzmann constant. This gives a value of $\epsilon$, which can be obtained from the control run. The effective atmospheric emissivity estimated this way shows some meridional differences depending on the climatological humidity and cloud cover at the different latitudes, but the low and high latitude averages are both 0.59. Using these values, we then obtain local estimates of the Planck feedback as

$$
\lambda_{0}=4 \epsilon \sigma T_{S A}^{3},
$$

and global, low- and high-latitude averages are given in Table 3. The lapse rate feedback is then calculated as $\lambda_{L R}=\lambda_{T}-\lambda_{0}$. In this manner, the heat transport change in the $\mathrm{CO} 2$ experiment that we took as part of $\lambda_{T}$ is thus taken more specifically as part of the lapse rate feedback. Whether to consider the heat transport as a separate feedback or as part of the 
other feedbacks is a matter of choice. Treating it separately makes in this case only a small difference for $\lambda_{L R}$, but as we begin next to consider the water vapor and cloud feedbacks, there would have to be separate heat transport feedbacks associated with each of them which would vary in both sign and magnitude. To avoid this confusing picture we have chosen to include the heat transport changes as part of the feedbacks that induce them.

The water vapor feedback including the associated heat transport change is now estimated from considering the rows labeled "Sum" in Table 2 corresponding to the situation where the system is forced by $\mathrm{F}_{\mathrm{CO} 2}$ and the water vapor feedback is turned on. The sum of the active feedbacks is given by the forcing and the temperature change as

$$
\lambda_{0}+\lambda_{L R}+\lambda_{w v}=-\frac{F_{C O 2}}{\Delta T_{C O 2}+\Delta T_{w v}},
$$

which permits us to determine the water vapor feedback $\lambda_{w v}$. We now estimate the cloud feedback including the associated heat transport change by finally also activating this in our linear framework. Knowing $\Delta T_{\text {cld }}($ glob, low, high $)=(0.07,0.02,0.12) \mathrm{K}$ and the other active feedbacks, we isolate $\lambda_{c l d}$ from

$$
\lambda=\lambda_{0}+\lambda_{L R}+\lambda_{w v}+\lambda_{c l d}=-\frac{F_{C O 2}}{\Delta T_{C O 2}+\Delta T_{w v}+\Delta T_{c l d}},
$$

and provide the results in the last row of Table 3. Here we made the assumption of linearity in the combination of effects, but using the experiments where the water vapor and cloud feedbacks are activated one at a time leads to results that are in very close correspondence. Given these estimates of the active feedbacks, we can calculate a temperature change as

$$
\Delta T=-\frac{F_{C O 2}}{\lambda_{0}+\lambda_{L R}+\lambda_{w v}+\lambda_{c l d}},
$$

where as before, all quantities are triplets of global, low- and high-latitude values.

We define polar amplification (PA) as the ratio of the high- to low-latitude warming and, inspired by Winton (2006), explore the effect on PA of the meridional differences in the quantities on the right hand side of the equation. We apply this with one feedback (or forcing) at a time, by replacing both their low- and high-latitude values by global mean 
values. In the standard case, where all feedbacks (and the forcing) retain their meridional differences, the PA is given as

$$
\mathrm{PA}=\frac{\Delta T^{h}}{\Delta T^{l}}=\frac{F_{C O 2}^{h}}{F_{C O 2}^{l}} \times \frac{\lambda_{0}^{l}+\lambda_{L R}^{l}+\lambda_{w v}^{l}+\lambda_{c l d}^{l}}{\lambda_{0}^{h}+\lambda_{L R}^{h}+\lambda_{w v}^{h}+\lambda_{c l d}^{h}}=0.80 \times 1.5=1.2,
$$

where superscripts $l$ and $h$ denote low and high latitudes, respectively. If a process is neutralized as described above and the resulting PA is greater than 1.2 , it means that the meridional differences in the process in question tend to act against PA and vice versa. From the results shown in the "PA uniform FB" column of Table 3 we see that the meridional shape of the lapse rate feedback acts in favor of PA. In fact, Figure $6 \mathrm{f}$ demonstrates that low-latitudes see a large decrease in lapse rate which allows the region to more easily radiate excess energy to space with only small surface temperature change. The meridional shape of the Planck feedback also acts in favor of PA. The combined temperature feedback $\lambda_{T}$ thus strongly favors PA, while the structure of the water vapor feedback and the $\mathrm{CO}_{2}$ forcing both counter PA. This particular model's weak cloud feedback is neutral in this regard and produces a PA of 1.2 as in the standard case when uniform values are used.

Neutralizing the meridional differences in a feedback is a different exercise from turning off the feedback altogether. The rightmost column of Table 3 shows the PA that results from setting the feedbacks to zero at both low and high latitudes in eqn. (11). Not all feedbacks are included here because turning off the Planck feedback yields negative climate sensitivity and non-sensible results. We note that turning off the the lapse rate feedback has an even more PA damping effect than merely neutralizing its meridional differences. Turning off the water vapor and cloud feedbacks lead both to a PA of 1.2, indicating that their inclusion makes no difference for the ratio of high- to low-latitude warming. In the case of the cloud feedback, it is simply because of its weakness. For the water vapor feedback, however, it is a different way of stating the result we found earlier (e.g., in Figure 4 a) that the water vapor feedback (incl. heat transport) doubles the local sensitivity and thereby maintains the same level of PA.

The omnipresent question of whether results obtained in one model will carry over to 
other models and, more importantly, to the real world is naturally also relevant here. However, comparison with Soden et al. (2008) and the feedback strengths arrived at in multimodel mean for the responses in their subset of 14 IPCC AR4 models using GFDL radiative kernels (their Figure 8) shows a convincing compatibility with the large-scale findings of this study. Their temperature feedback, $\lambda_{T}$, has a global average of $-4.2 \mathrm{~W} \mathrm{~m}^{-2} \mathrm{~K}^{-1}$, the same number we arrive at. Typical low-latitude values are $-5 \mathrm{~W} \mathrm{~m}^{-2} \mathrm{~K}^{-1}$ and high-latitude values vary between about -2.5 and $-4.5 \mathrm{~W} \mathrm{~m}^{-2} \mathrm{~K}^{-1}$. For comparison our low- and high-latitude values are -5.1 and $-3.5 \mathrm{~W} \mathrm{~m}^{-2} \mathrm{~K}^{-1}$, respectively. For the water vapor feedback, Soden et al. (2008) find a global mean value of $1.9 \mathrm{~W} \mathrm{~m}^{-2} \mathrm{~K}^{-1}$ with typical low-latitude values of about $3 \mathrm{~W} \mathrm{~m}^{-2} \mathrm{~K}^{-1}$ and high-latitude values close to $1 \mathrm{~W} \mathrm{~m}^{-2} \mathrm{~K}^{-1}$. Our global mean value is in close agreement $\left(2.1 \mathrm{~W} \mathrm{~m}^{-2} \mathrm{~K}^{-1}\right)$, while our low- $\left(2.5 \mathrm{~W} \mathrm{~m}^{-2} \mathrm{~K}^{-1}\right)$ and high-latitude $\left(1.8 \mathrm{~W} \mathrm{~m}^{-2} \mathrm{~K}^{-1}\right)$ values are lower and higher, respectively. While the global mean value is close, the meridional gradient in our numbers is thus lower, consistent with our choice of including in the feedback the heat transport contribution associated with the WV change.

Although Soden et al. (2008) find regional variations in the feedback strength linked, for instance, to land-ocean contrasts and the Pacific Walker cell, the most striking feature is the very zonally symmetric structure apparent in both the temperature and water vapor feedbacks. This is due to the structure of the temperature field which bears the same characteristic and gives us confidence that our aquaplanet model configuration which targets exactly the zonally symmetric features does capture the most fundamental of effects. The fact that the numbers are so close in magnitude reflects the fact that the temperature and water vapor feedbacks are among the most consistent across models and likely also most faithfully represented and well-understood. The cloud feedback values vary both in sign and magnitude across the calculations of Soden et al. (2008) reflecting the large inter-model spread in cloud responses and we consequently place low confidence in our cloud-related results. Including land and sea ice would allow for albedo feedbacks at high-latitudes and this would further boost the polar warming leading to an increase in the water vapor response 
and feedback. Again, if the water vapor feedback tends to double local sensitivity, an extra positive feedback would also be mirrored in the water vapor feedback.

\section{Conclusions}

The NCAR CAM3 atmospheric GCM has been modified to accommodate an on-line locking of the water vapor and cloud feedbacks. This is done by reading in hourly fields of water vapor and the five variables characterizing the cloud optical properties to the model's radiation code from either a $1 \times \mathrm{CO}_{2}$ or $2 \times \mathrm{CO}_{2}$ equilibrium climate. To simplify the system and thereby ease the interpretation, we have used aquaplanet lower boundary conditions, excluded sea ice and fixed the surface albedo in all grid points. The latter change completely disables the surface albedo feedback from all our experiments. This idealized configuration has allowed us to isolate the temperature, water vapor and cloud feedbacks before progressing to a more complete system in future studies.

We concluded that correlations between the water vapor and cloud fields would lead to biases when fields from different climates were combined and the solution was to shift the two relative to each other by one year even in the control experiment. The global average radiative effect of the water vapor change was found to be almost equal to the $\mathrm{CO}_{2}$ forcing, namely about $3.5 \mathrm{~W} \mathrm{~m}^{-2}$. The meridional structure was different, however, with a larger weight on the low latitudes. The cloud feedback was found to give a very small global average radiative effect.

When the model was run with a slab ocean configuration we were able to see directly the climate change associated with the individual feedbacks and the forcing. Importantly for the soundness of the method, we found that the sum of the responses to the individual feedbacks and the forcing add up quite accurately to the full response with all included simultaneously, although a slight non-linearity is introduced by the clouds. Moreover, the locked-feedbacks experiment with all effects included gave the same response as the free-feedbacks experiment, 
demonstrating that our method of de-correlating the input fields and considering the effects individually is viable way of decomposing the free-feedbacks experiment.

The CO2 and WV experiments give very similar responses although the TOA radiative effects of the two are quite different. We found that the meridional heat transport adjusts so as to exactly counter the differences and produce similar responses. This is compatible with earlier studies suggesting that the climate system possesses a preferred pattern of response near-independent of the forcing. The adjustment occurs in part due to an increase in the mid-latitude dry static energy transport, which is found in the WV experiment even in the face of a decreased meridional temperature gradient. We suspect that the larger mid-latitude latent heat release compared to the $\mathrm{CO} 2$ experiment reinforces the eddies relative to what is to be expected from dry dynamic theory and thereby increases the eddy heat transport.

By estimating feedback factors for the different feedback mechanisms, both globally and for low and high latitudes separately, we conclude that the water vapor feedback does not in itself lead to polar amplification. In fact, we saw that its meridional structure tends to quite strongly counteract PA. It does, however, tend to double local climate sensitivity, so that if other feedbacks produce PA, as the Planck and lapse rate feedbacks do here, the amount of high-latitude warming will be enhanced. The direct radiative effect of the water vapor feedback is responsible for part of this while the heat transport change associated with water vapor contributes further.

While our conclusions may depend on the particular choice of model or experimental configuration, the temperature and water vapor feedbacks and their meridional structure compare well with those of the multi-model mean of IPCC AR4 models (Soden et al. 2008). Inter-model spread is generally high for the cloud feedback and we have low confidence in the robustness of our cloud-related results. On the other hand, the hemispheric-scale, zonally averaged features of the temperature and water vapor feedbacks and related conclusions are expected to carry over to more complete configurations. Inclusion of land, topography and sea ice will, however, potentially influence the regional specifics of the interplay between 
feedbacks.

Acknowledgments.

This work was supported in part by a grant of HPC resources from the Arctic Region Supercomputing Center (ARSC) at the University of Alaska Fairbanks as part of the Department of Defense High Performance Computing Modernization Program. We thank three anonymous reviewers whose comments helped us improve both the clarity and conclusions of the manuscript. 

REFERENCES

Alexeev, V. A., 2003: Sensitivity to $\mathrm{CO}_{2}$ doubling of an atmospheric GCM coupled to an oceanic mixed layer: a linear analysis. Clim. Dyn., 20, 775-787.

Andrews, T. and P. M. Forster, 2008: $\mathrm{CO}_{2}$ forcing induces semi-direct effects with consequences for climate feedback interpretations. Geophys. Res. Lett., 35, L04802,.

Bitz, C. M., 2008: Some aspects of uncertainty in predicting sea ice retreat. in Arctic Sea Ice Decline: observations, projections, mechanisms, and implications. AGU Geophysical Monograph Series, 189, 269 pp.

Boer, G. J. and B. Yu, 2003: Climate sensitivity and response. Clim. Dyn., 20, 415-429.

Collins, W. D., et al., 2006: The formulation and atmospheric simulation of the Community Atmosphere Model: CAM3. J. Climate, 19 (11), 2144-2161.

Colman, R., 2003: A comparison of climate feedbacks in general circulation models. Clim. Dyn., 20, 865-873.

Colman, R. A. and B. J. McAvaney, 1997: A study of general circulation model climate feedbacks determined from perturbed sea surface temperature experiments. J. Geophys. Res., 102, $19383-19402$.

Cubasch, U., R. Voss, G. C. Hegerl, J. Waszkewitz, and T. J. Crowley, 1997: Simulation of the influence of solar radiation variations on the global climate with an ocean-atmosphere general circulation model. Clim. Dyn., 13, 757-767.

Dufresne, J.-L. and S. Bony, 2008: An assessment of the primary sources of spread of global warming estimates from coupled atmosphereocean models. J. Climate, 21, 5135-5144. 
Emanuel, K. A., M. Fantini, and A. J. Thorpe, 1987: Baroclinic instability in an environment of small stability to slantwise moist convection. Part i: Two-dimensional models. J. Atmos. Sci., 44 (12), 1559-1573.

Graversen, R. G., 2006: Do changes in the midlatitude circulation have any impact on the Arctic surface air temperature trend? J. Climate, 19, 5422-5438.

Graversen, R. G., T. Mauritsen, M. Tjernström, E. Källén, and G. Svensson, 2008: Vertical structure of recent Arctic warming. Nature, 541, 53-56.

Graversen, R. G. and M. Wang, 2009: Polar amplification in a coupled climate model with locked albedo. Clim. Dyn., 33, 629-643.

Gregory, J. and M. Webb, 2008: Tropospheric adjustment induces a cloud component in $\mathrm{CO}_{2}$ forcing. J. Climate, 21, 58-71.

Hall, A., 2004: The role of surface albedo feedback in climate. J. Climate, 17, 1550-1568.

Hall, A. and S. Manabe, 1999: The role of water vapor feedback in unperturbed climate variability and global warming. J. Climate, 12, 2327-2346.

Hansen, J., A. Lacis, D. Rind, G. Russell, P. Stone, I. Fung, R. Ruedy, and J. Lerner, 1994: Climate sensitivity: Analysis of feedback mechanisms. In Climate Processes and Climate Sensitivity, AGU Geophysical Monograph 29, Maurice Ewing Vol. 5., 130-163.

Hansen, J., et al., 2005: Efficacy of climate forcings. J. Geophys. Res., 110 (D18104).

Held, I. M. and B. J. Soden, 2000: Water vapor feedback and global warming. Annu. Rev. Energy Environ., 25, 441-475.

Holland, M. M. and C. M. Bitz, 2003: Polar amplification of climate change in coupled models. Clim. Dyn., 21, 221-232. 
Hoskins, B. J. and P. J. Valdes, 1990: On the existence of storm-tracks. J. Atmos. Sci., 47, $1854-1864$.

Johannessen, O. M., et al., 2004: Arctic climate change: observed and modelled temperature and sea-ice variability. Tellus, 56A, 328-341.

Kiehl, J. T., C. A. Shields, J. J. Hack, and W. D. Collins, 2006: The climate sensitivity of the Community Climate System Model Version 3 (CCSM3). J. Climate, 19, 2584-2596.

Langen, P. L. and V. A. Alexeev, 2007: Polar amplification as a preferred response in an idealized aquaplanet GCM. Clim. Dyn., 29, 305-317.

Langen, P. L. and R. Caballero, 2007: Cloud variability, radiative forcing and meridional temperature gradients in a general circulation model. Tellus, 59A, 641-649.

Manabe, S. and R. J. Stouffer, 1980: Sensitivity of a global climate model to an increase of $\mathrm{CO}_{2}$ concentration in the atmosphere. J. Geophys. Res., 85, 5529-5554.

Manabe, S. and R. T. Wetherald, 1975: The effects of doubling the $\mathrm{CO}_{2}$ concentration on the climate of a general circulation model. J. Atmos. Sci., 32, 3-15.

Manabe, S. and R. T. Wetherald, 1980: On the distribution of climate change resulting from an increase in the $\mathrm{CO}_{2}$ content of the atmosphere. J. Atmos. Sci., 37, 99-118.

Polyakov, I. V., et al., 2010: Arctic Ocean warming contributes to reduced polar ice cap. J. Phys. Ocean., 40, 2743-2756.

Ramanathan, V., R. D. Cess, E. F. Harrison, P. Minnis, B. R. Barkstrom, E. Ahmad, and D. Hartmann, 1989: Cloud-radiative forcing and climate: Results from the earth radiation budget experiment. Science, 243, 57-63.

Rigor, I. G., R. L. Colony, and S. Martin, 2000: Variations in surface air temperature observations in the Arctic, 1979-97. J. Climate, 13, 896-914. 
Schneider, E. K., B. P. Kirtman, and R. S. Lindzen, 1999: Tropospheric water vapor and climate sensitivity. J. Atmos. Sci., 56, 1649-1658.

Schneider, S. H., 1972: Cloudiness as a global climatic feedback mechanism: The effects on the radiation balance and surface temperature of variations in cloudiness. J. Atmos. Sci., 29, 1413-1422.

Screen, J. A. and I. Simmonds, 2010a: The central role of diminishing sea ice in recent Arctic temperature amplification. Nature, 464, 1334-1337.

Screen, J. A. and I. Simmonds, 2010b: Increasing fall?winter energy loss from the Arctic Ocean and its role in Arctic temperature amplification. Geophys. Res. Lett., 37, L16 707.

Serreze, M., A. Barrett, J. Stroeve, D. Kindig, and M. Holland, 2009: The emergence of surface-based arctic amplification. The Crysophere, 3, 11-19.

Shindell, D. and G. Faluvegi, 2009: Climate response to regional radiative forcing during the twentieth century. Nature Geosci., 2, 294-300.

Shine, K. P., J. Cook, E. J. Highwood, and M. M. Joshi, 2003: An alternative to radiative forcing for estimating the relative importance of climate change mechanisms. Geophys. Res. Lett., 30 (20), 2047.

Soden, B. J. and I. M. Held, 2006: An assessment of climate feddbacks in coupled oceanatmosphere models. J. Climate, 19, 3354-3360.

Soden, B. J., I. M. Held, R. Colman, K. M. Shell, J. T. Kiehl, and C. A. Shields, 2008: Quantifying climate feedbacks using radiative kernels. J. Climate, 21, 3504-3520.

Spielhagen, R. F., et al., 2011: Enhanced modern heat transfer to the Arctic by warm Atlantic water. Science, 331, 450-453. 
Stone, P. H. and M. S. Yao, 1990: Development of a two-dimensional zonally averaged statistical-dynamical model. Part III: The parameterization of the eddy fluxes of heat and moisture. J. Climate, 3, 726-740.

Vavrus, S. J., 2004: The impact of cloud feedbacks on arctic climate under greenhouse forcing. J. Climate, 17, 603-615.

Wetherald, R. T. and S. Manabe, 1988: Cloud feedback processes in a general circulation model. J. Atmos. Sci., 45, 1397-1415.

Winton, M., 2006: Amplified Arctic climate change: What does surface albedo feedback have to do with it? Geophys. Res. Lett., 33, L03 701, doi:10.1029/2005GL025 244.

Zhang, M. H., J. J. Hack, J. T. Kiehl, and R. D. Cess, 1994: Diagnostic study of climate feedback processes in atmospheric general circulation models. J. Geophys. Res., 99 (18), $5525-5538$.

Zhang, X., A. Sorteberg, J. Zhang, R. Gerdes, and J. C. Comiso, 2008: Recent radical shifts of atmospheric circulations and rapid changes in Arctic climate system. Geophys. Res. Lett., 35, doi:10.1029/2008GL035 607. 


\section{List of Tables}

1 Overview over data ocean model (dom) experiments (upper half) and the slab ocean experiments (lower half). The naming of the experiments indicates the amount of $\mathrm{CO}_{2}$ in the atmosphere (if $\mathrm{CO} 2$ is in the name it is $2 \times$ ), whether water vapor has been taken from the $2 \times \mathrm{CO}_{2}$ run (if WV enters the name), whether the five cloud parameter fields have been taken from $2 \times \mathrm{CO}_{2}$ (if CLD enters the name), and whether the water vapor and cloud fields have been shifted by 1 year relative to each other (shift). All slab ocean experiments were performed with water vapor and clouds shifted.

2 Rad effect: The global average, low-latitude (0-30 $)$ average and mid-to-highlatitude $\left(30-90^{\circ}\right)$ average of the direct radiative effect due to $\mathrm{CO}_{2}$ and $\mathrm{WV}$ (and their sum). Transport: The area average energy input due to the change in meridional energy transport across $30^{\circ}$. Rad+Transp: The sum of the above. Response: The surface temperature changes in the two experiments. The numbers in italic are referred to in the text.

3 Global, low- and high-latitude values of the estimated feedback parameters in units of $\mathrm{W} \mathrm{m}^{-2} \mathrm{~K}^{-1}$ (forcing values are in $\mathrm{W} \mathrm{m}^{-2}$ ). In the two last columns, polar amplifications are calculated as the ratio of high- to low-latitude warming. The PA is calculated both by using the global average value of the particular feedback (or forcing) at both low and high latitudes "PA uniform FB" and by setting the feedback to zero at both low and high latitudes ("PA zero FB"). 
TABle 1. Overview over data ocean model (dom) experiments (upper half) and the slab ocean experiments (lower half). The naming of the experiments indicates the amount of $\mathrm{CO}_{2}$ in the atmosphere (if $\mathrm{CO} 2$ is in the name it is $2 \times$ ), whether water vapor has been taken from the $2 \times \mathrm{CO}_{2}$ run (if WV enters the name), whether the five cloud parameter fields have been taken from $2 \times \mathrm{CO}_{2}$ (if CLD enters the name), and whether the water vapor and cloud fields have been shifted by 1 year relative to each other (shift). All slab ocean experiments were performed with water vapor and clouds shifted.

\begin{tabular}{lcccc}
\hline Experiment & $\mathrm{CO}_{2}$ conc & Water vapor & Cloud & shifted \\
\hline domCTRL & $1 \times$ & $1 \times$ & $1 \times$ & \\
domCTRLshift & $1 \times$ & $1 \times$ & $1 \times$ & $1 \mathrm{yr}$ \\
domCLD & $1 \times$ & $1 \times$ & $2 \times$ & \\
domWV & $1 \times$ & $2 \times$ & $1 \times$ & \\
domWV\&CLD & $1 \times$ & $2 \times$ & $2 \times$ & \\
domWV\&CLDshift & $1 \times$ & $2 \times$ & $2 \times$ & $1 \mathrm{yr}$ \\
domCO2shift & $2 \times$ & $1 \times$ & $1 \times$ & $1 \mathrm{yr}$ \\
\hline CTRL & $1 \times$ & $1 \times$ & $1 \times$ & $1 \mathrm{yr}$ \\
CLD & $1 \times$ & $1 \times$ & $2 \times$ & \\
WV & $1 \times$ & $2 \times$ & $1 \times$ & \\
WV\&CLD & $1 \times$ & $2 \times$ & $2 \times$ & $1 \mathrm{yr}$ \\
CO2 & $2 \times$ & $1 \times$ & $1 \times$ & $1 \mathrm{yr}$ \\
CO2\&CLD & $2 \times$ & $1 \times$ & $2 \times$ & \\
CO2\&WV & $2 \times$ & $2 \times$ & $1 \times$ & \\
CO2\&WV\&CLD & $2 \times$ & $2 \times$ & $2 \times$ & $1 \mathrm{yr}$ \\
\hline
\end{tabular}


TABLE 2. Rad effect: The global average, low-latitude $\left(0-30^{\circ}\right)$ average and mid-to-highlatitude $\left(30-90^{\circ}\right)$ average of the direct radiative effect due to $\mathrm{CO}_{2}$ and WV (and their sum). Transport: The area average energy input due to the change in meridional energy transport across $30^{\circ}$. Rad+Transp: The sum of the above. Response: The surface temperature changes in the two experiments. The numbers in italic are referred to in the text.

\begin{tabular}{lcccc}
\hline & & Global & $0-30^{\circ}$ & $30-90^{\circ}$ \\
\hline Rad effect & & & & \\
$\mathrm{CO}_{2}$ & $\left(\mathrm{~W} \mathrm{~m}^{-2}\right)$ & 3.4 & 3.8 & 3.0 \\
$\mathrm{WV}$ & $\left(\mathrm{W} \mathrm{m}^{-2}\right)$ & 3.5 & 4.6 & 2.4 \\
Sum & $\left(\mathrm{W} \mathrm{m}^{-2}\right)$ & $\mathbf{6 . 9}$ & $\mathbf{8 . 4}$ & $\mathbf{5 . 4}$ \\
\hline Transport & & & & \\
$\mathrm{CO}_{2}$ & $\left(\mathrm{~W} \mathrm{~m}^{-2}\right)$ & 0 & 0.1 & -0.1 \\
WV & $\left(\mathrm{W} \mathrm{m}^{-2}\right)$ & 0 & -0.5 & 0.5 \\
Sum & $\left(\mathrm{W} \mathrm{m}^{-2}\right)$ & $\mathbf{0}$ & $\mathbf{- 0 . 4}$ & $\mathbf{0 . 4}$ \\
\hline Rad+Transp & & & & \\
$\mathrm{CO}$ & $\left(\mathrm{W} \mathrm{m}^{-2}\right)$ & 3.4 & 3.9 & 2.9 \\
$\mathrm{WV}_{\text {Sum }}$ & $\left(\mathrm{W} \mathrm{m}{ }^{-2}\right)$ & 3.5 & 4.1 & 2.9 \\
\hline Response & $\left(\mathrm{W} \mathrm{m}{ }^{-2}\right)$ & $\mathbf{6 . 9}$ & $\mathbf{8 . 0}$ & $\mathbf{5 . 8}$ \\
$\mathrm{CO}_{2}$ & $(\mathrm{~K})$ & 0.80 & 0.74 & 0.86 \\
$\mathrm{WV}_{\text {Sum }}$ & $(\mathrm{K})$ & 0.81 & 0.75 & 0.87 \\
\hline
\end{tabular}


TABLE 3. Global, low- and high-latitude values of the estimated feedback parameters in units of $\mathrm{W} \mathrm{m}^{-2} \mathrm{~K}^{-1}$ (forcing values are in $\mathrm{W} \mathrm{m}^{-2}$ ). In the two last columns, polar amplifications are calculated as the ratio of high- to low-latitude warming. The PA is calculated both by using the global average value of the particular feedback (or forcing) at both low and high latitudes "PA uniform FB" and by setting the feedback to zero at both low and high latitudes ("PA zero FB").

\begin{tabular}{llrrrcc}
\hline Feedback & Symbol & Global & $0-30^{\circ}$ & $30-90^{\circ}$ & PA uniform FB & PA zero FB \\
\hline Full & $\lambda$ & -2.0 & -2.5 & -1.6 & $\mathbf{1 . 2}$ & \\
Forcing & $F_{C O 2}$ & 3.4 & 3.8 & 3.0 & 1.5 & \\
Temperature & $\lambda_{T}$ & -4.2 & -5.1 & -3.5 & 0.57 & \\
Planck & $\lambda_{0}$ & -3.2 & -3.5 & -3.0 & 0.95 & \\
Lapse rate & $\lambda_{L R}$ & -1.0 & -1.6 & -0.54 & 0.73 & 0.66 \\
Water vapor & $\lambda_{w v}$ & 2.1 & 2.5 & 1.8 & 1.8 & 1.2 \\
Cloud & $\lambda_{\text {cld }}$ & 0.088 & 0.032 & 0.12 & 1.2 & 1.2 \\
\hline
\end{tabular}




\section{List of Figures}

1 (a) Annual and zonal average surface temperatures $(K)$ in the equilibrium $1 \times \mathrm{CO}_{2}$ and $2 \times \mathrm{CO}_{2}$ climates in the "free" runs with interactively calculated clouds and moisture (left axis) and the temperature change (dT) calculated as the difference between the two (right axis). (b) and (c) Annual and zonal average water vapor $(\mathrm{kg} / \mathrm{kg})$ and cloud fraction changes between the $1 \times \mathrm{CO}_{2}$ and $2 \times \mathrm{CO}_{2}$ climates.

2 (a) Radiative effect of moisture and cloud de-correlation with $1 \times \mathrm{CO}_{2}$ (solid, domCTRLshift-domCTRL) and with $2 \times \mathrm{CO}_{2}$ moisture and clouds (dashed, domWV\&CLDshift-domWV\&CLD). (b) Radiative effect of changing cloud and moisture fields from their $1 \times \mathrm{CO}_{2}$ to their $2 \times \mathrm{CO}_{2}$ climatologies when they have been shifted (solid, domWV\&CLDshift-domCTRLshift) and when they are simultaneous (dashed, domWV\&CLD-domCTRL).

3 (a) Radiative effect or forcing due to changing water vapor (solid, domWV-domCTRLshift) and $\mathrm{CO}_{2}$ (dashed, domCO2shift-domCTRLshift). (b) Radiative effect of changing cloud fields (domCLD-domCTRLshift). These are all evaluated as the top-of-atmosphere change in fixed SST experiments.

4 (a) Surface temperature change $(\mathrm{K})$ in slab ocean experiments due to $\mathrm{CO}_{2}$ changes (dashed, CO2-CTRL), water vapor changes (solid, WV-CTRL) and cloud changes (dotted, CLD-CTRL). (b) Temperature change (K) with all effects changed (solid, CO2\&WV\&CLD-CTRL) compared to the sum of the curves in panel (a) (dashed) and the change in the "free" experiments with interactively calculated clouds and moisture (dotted). Curves in all panels have been symmetrized about the equator. 
(a) Surface temperature change $(\mathrm{K})$ due to changing water vapor in a $1 \times \mathrm{CO}_{2}$ background climate (solid, WV-CTRL) and a $2 \times \mathrm{CO}_{2}$ background climate (dashed, CO2\&WV\&CLD-CO2\&CLD). (b) As in (a) but for cloud fields. Curves in all panels have been symmetrized about the equator.

6 Annual and zonal average atmospheric temperature change $(\mathrm{K})$ due to changing clouds (a, CLD-CTRL), changing water vapor (b, WV-CTRL), changing $\mathrm{CO}_{2}$ (c, CO2-CTRL) and changing all three (d, CO2\&WV\&CLD-CTRL). For comparison is shown (e) the sum of the changes $(a)+(b)+(c)$ and the change in the "free" experiments with interactively calculated clouds and moisture. All panels have been symmetrized.

$7 \quad$ Northward atmospheric energy transport changes (PW). (a) Total moist static energy transport change due to changing water vapor (solid) and $\mathrm{CO}_{2}$ (dashed). (b) and (c) as in (a) but for dry static energy and latent heat components. Also shown in panels (a)-(c) is the full value of the transport in the background climate (in grey, right axis). (d)-(f) Total moist static energy, dry static energy and latent heat transport changes due to changing both water vapor and $\mathrm{CO}_{2}$ (solid) and the sum of the changes in the panels above (dashed) for comparison. All panels have been anti-symmetrized.

8 (a) Change in lower-tropospheric (900-500 hPa) averaged Eady growth rate, $\sigma_{B I}$, as defined in the text. Shown are WV-CTRL (solid) and CO2-CTRL (dashed). (b) The same but for 900-500 hPa averaged eddy kinetic energy. (c) Relative change in meridional temperature gradient also averaged 900-500 hPa. 
9 (a) Zonal mean meridional mass streamfunction in the control climate (CTRL) at latitudes $-60^{\circ}$ to $60^{\circ}$. (b) and (c) Changes due to moisture (WV-CTRL) and $\mathrm{CO}_{2}(\mathrm{CO} 2-\mathrm{CTRL})$, respectively. (d) Zonal mean difference in heating rate due to latent heat release between the $\mathrm{WV}$ and $\mathrm{CO}_{2}$ experiments (WV-CO2). 

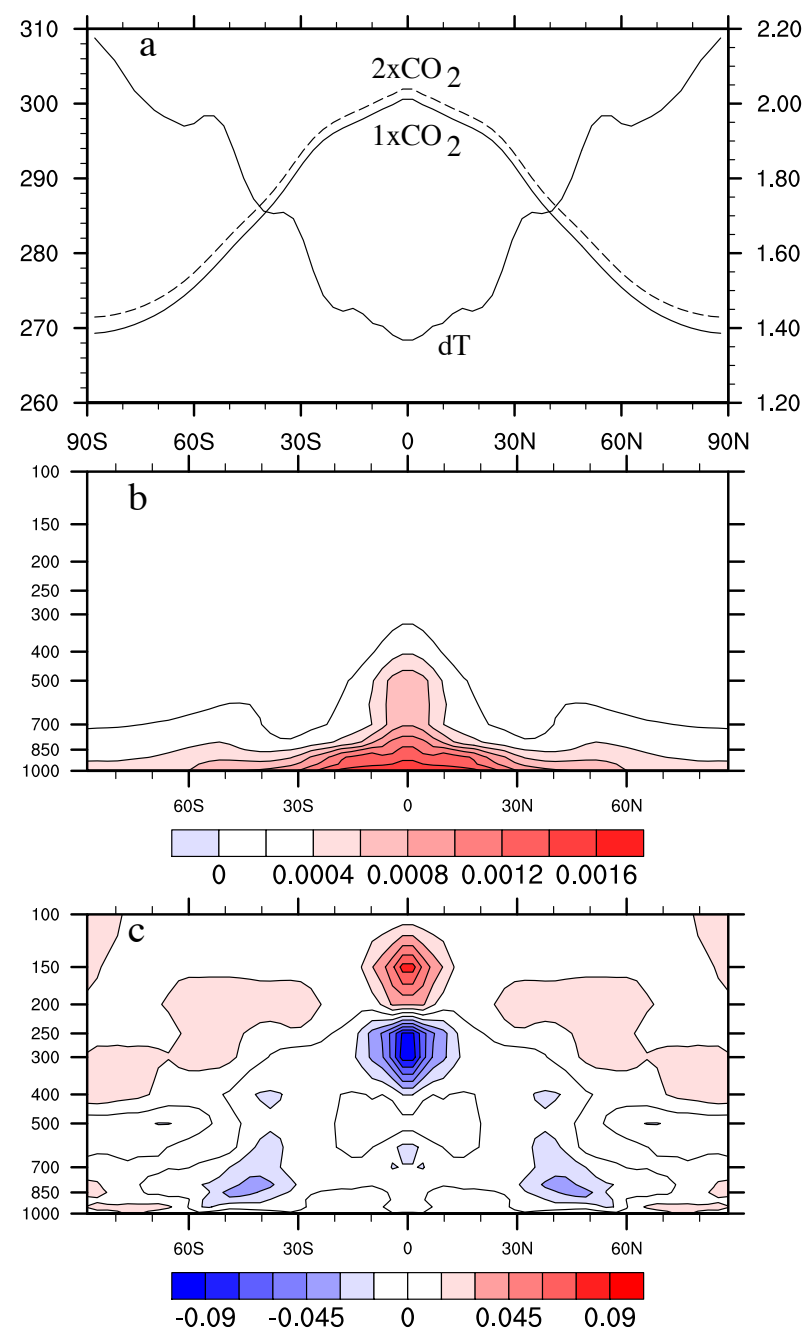

FIG. 1. (a) Annual and zonal average surface temperatures $(\mathrm{K})$ in the equilibrium $1 \times \mathrm{CO}_{2}$ and $2 \times \mathrm{CO}_{2}$ climates in the "free" runs with interactively calculated clouds and moisture (left axis) and the temperature change (dT) calculated as the difference between the two (right axis). (b) and (c) Annual and zonal average water vapor (kg/kg) and cloud fraction changes between the $1 \times \mathrm{CO}_{2}$ and $2 \times \mathrm{CO}_{2}$ climates. 


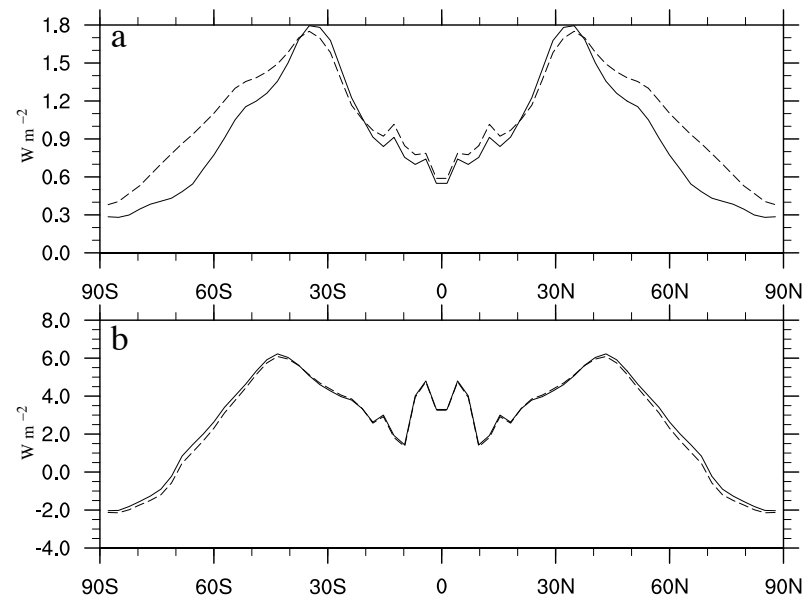

FIG. 2. (a) Radiative effect of moisture and cloud de-correlation with $1 \times \mathrm{CO}_{2}$ (solid, domCTRLshift-domCTRL) and with $2 \times \mathrm{CO}_{2}$ moisture and clouds (dashed, domWV\&CLDshift-domWV\&CLD). (b) Radiative effect of changing cloud and moisture fields from their $1 \times \mathrm{CO}_{2}$ to their $2 \times \mathrm{CO}_{2}$ climatologies when they have been shifted (solid, domWV\&CLDshift-domCTRLshift) and when they are simultaneous (dashed, domWV\&CLD-domCTRL). 


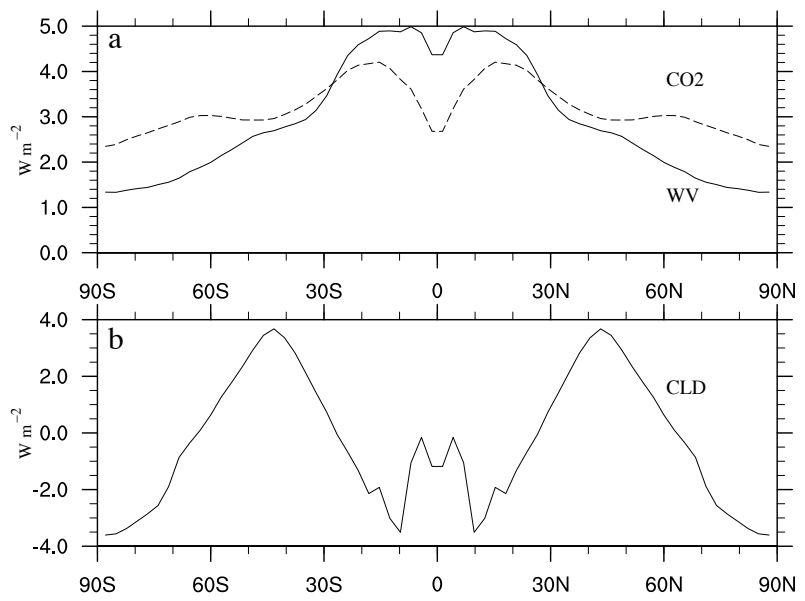

FIG. 3. (a) Radiative effect or forcing due to changing water vapor (solid, domWV-domCTRLshift) and $\mathrm{CO}_{2}$ (dashed, domCO2shift-domCTRLshift). (b) Radiative effect of changing cloud fields (domCLD-domCTRLshift). These are all evaluated as the top-of-atmosphere change in fixed SST experiments. 


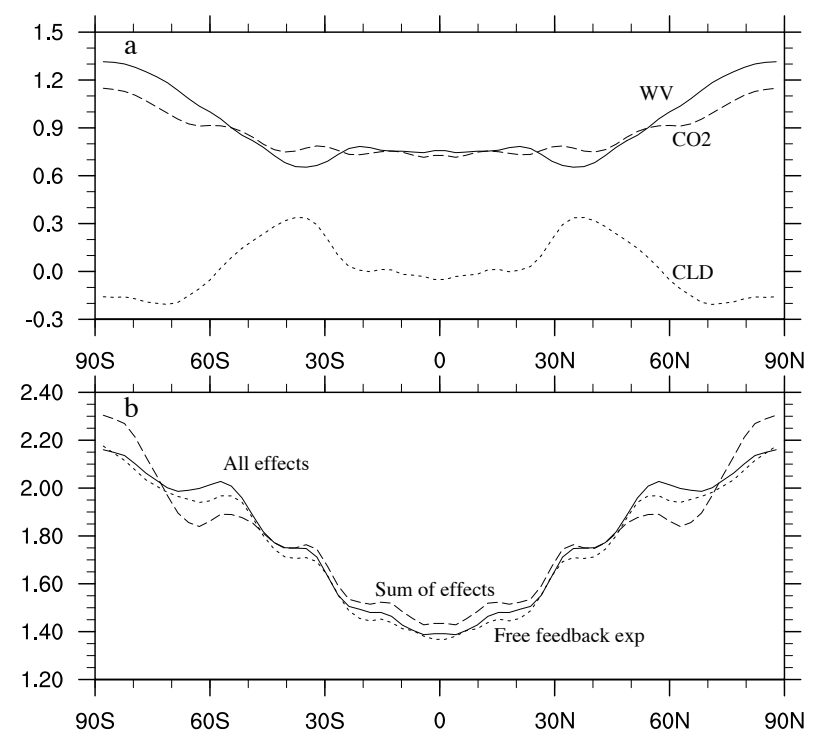

FIG. 4. (a) Surface temperature change (K) in slab ocean experiments due to $\mathrm{CO}_{2}$ changes (dashed, CO2-CTRL), water vapor changes (solid, WV-CTRL) and cloud changes (dotted, CLD-CTRL). (b) Temperature change (K) with all effects changed (solid, CO2\&WV\&CLD-CTRL) compared to the sum of the curves in panel (a) (dashed) and the change in the "free" experiments with interactively calculated clouds and moisture (dotted). Curves in all panels have been symmetrized about the equator. 

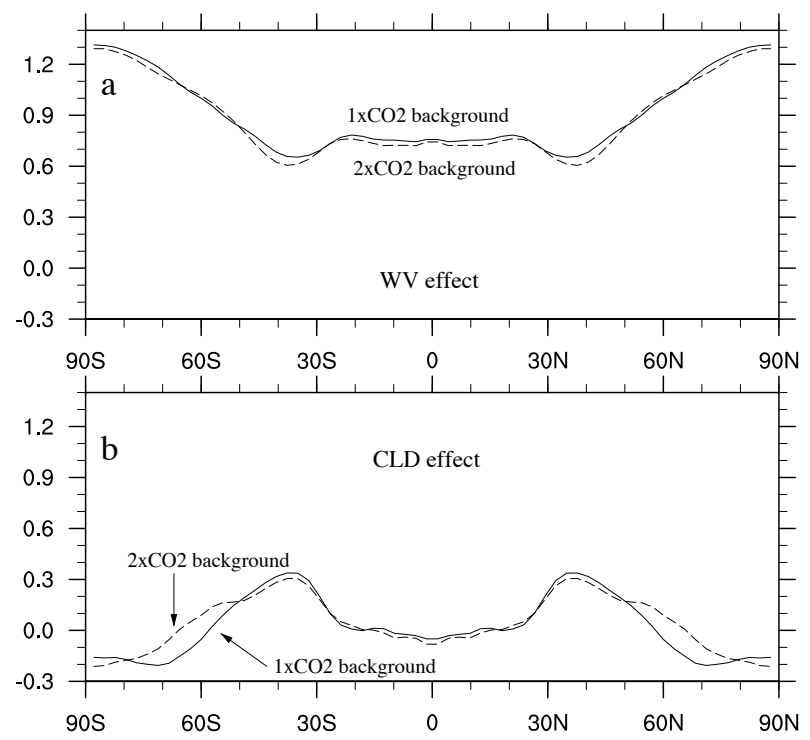

FIG. 5. (a) Surface temperature change $(\mathrm{K})$ due to changing water vapor in a $1 \times \mathrm{CO}_{2}$ background climate (solid, WV-CTRL) and a $2 \times \mathrm{CO}_{2}$ background climate (dashed, CO2\&WV\&CLD-CO2\&CLD). (b) As in (a) but for cloud fields. Curves in all panels have been symmetrized about the equator. 

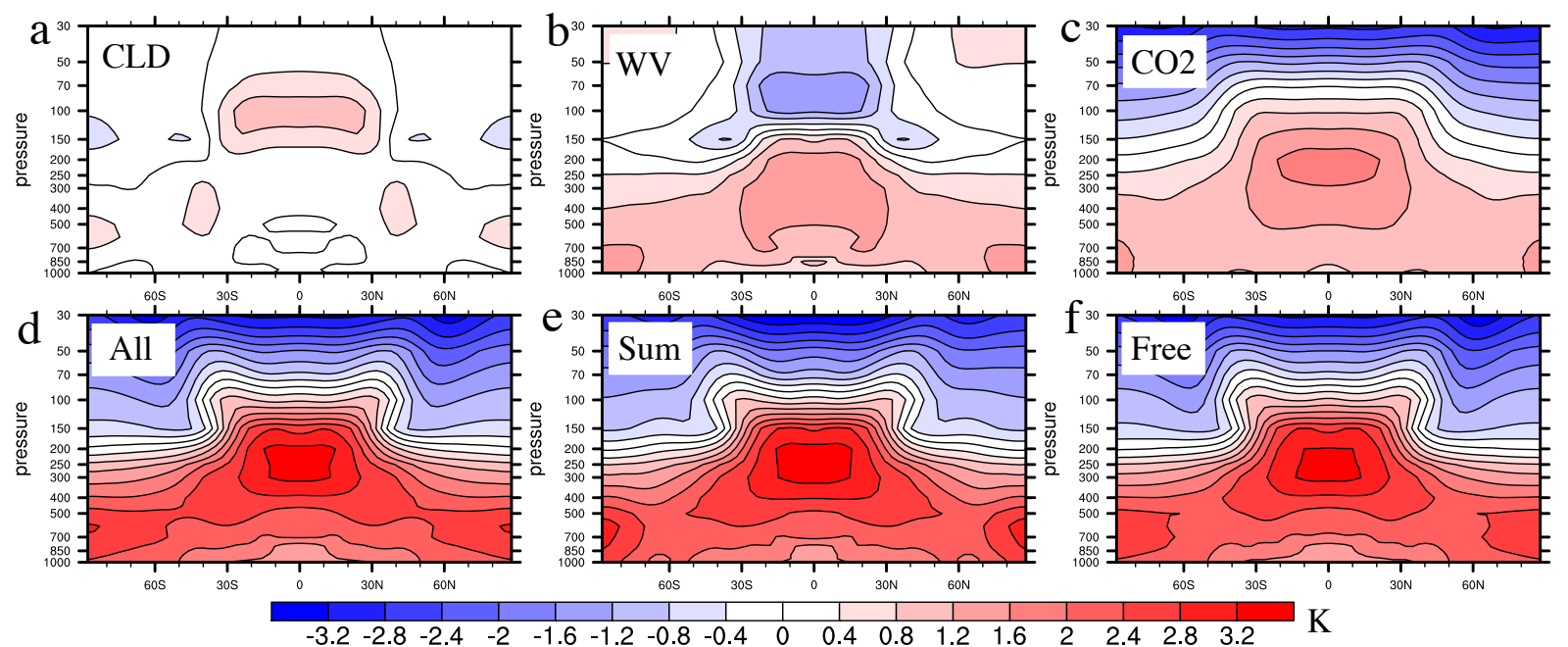

FIG. 6. Annual and zonal average atmospheric temperature change $(\mathrm{K})$ due to changing clouds (a, CLD-CTRL), changing water vapor (b, WV-CTRL), changing $\mathrm{CO}_{2}$ (c, CO2-CTRL) and changing all three (d, CO2\&WV\&CLD-CTRL). For comparison is shown (e) the sum of the changes $(\mathrm{a})+(\mathrm{b})+(\mathrm{c})$ and the change in the "free" experiments with interactively calculated clouds and moisture. All panels have been symmetrized. 

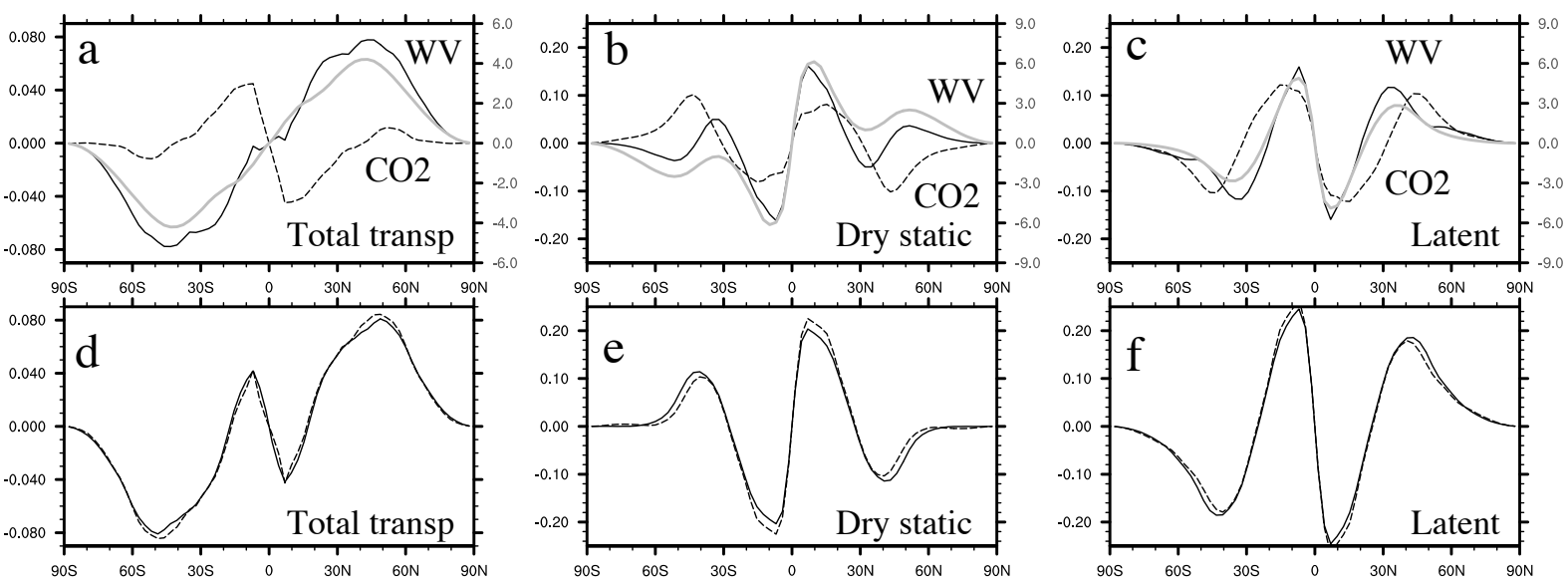

FIG. 7. Northward atmospheric energy transport changes (PW). (a) Total moist static energy transport change due to changing water vapor (solid) and $\mathrm{CO}_{2}$ (dashed). (b) and (c) as in (a) but for dry static energy and latent heat components. Also shown in panels (a)-(c) is the full value of the transport in the background climate (in grey, right axis). (d)-(f) Total moist static energy, dry static energy and latent heat transport changes due to changing both water vapor and $\mathrm{CO}_{2}$ (solid) and the sum of the changes in the panels above (dashed) for comparison. All panels have been anti-symmetrized. 

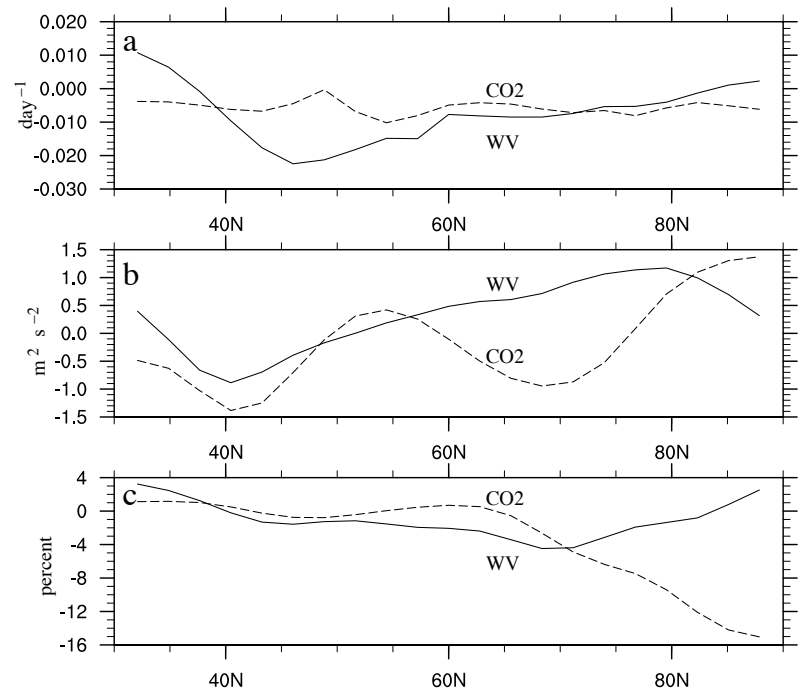

FIG. 8. (a) Change in lower-tropospheric (900-500 hPa) averaged Eady growth rate, $\sigma_{B I}$, as defined in the text. Shown are WV-CTRL (solid) and CO2-CTRL (dashed). (b) The same but for 900-500 hPa averaged eddy kinetic energy. (c) Relative change in meridional temperature gradient also averaged 900-500 hPa. 

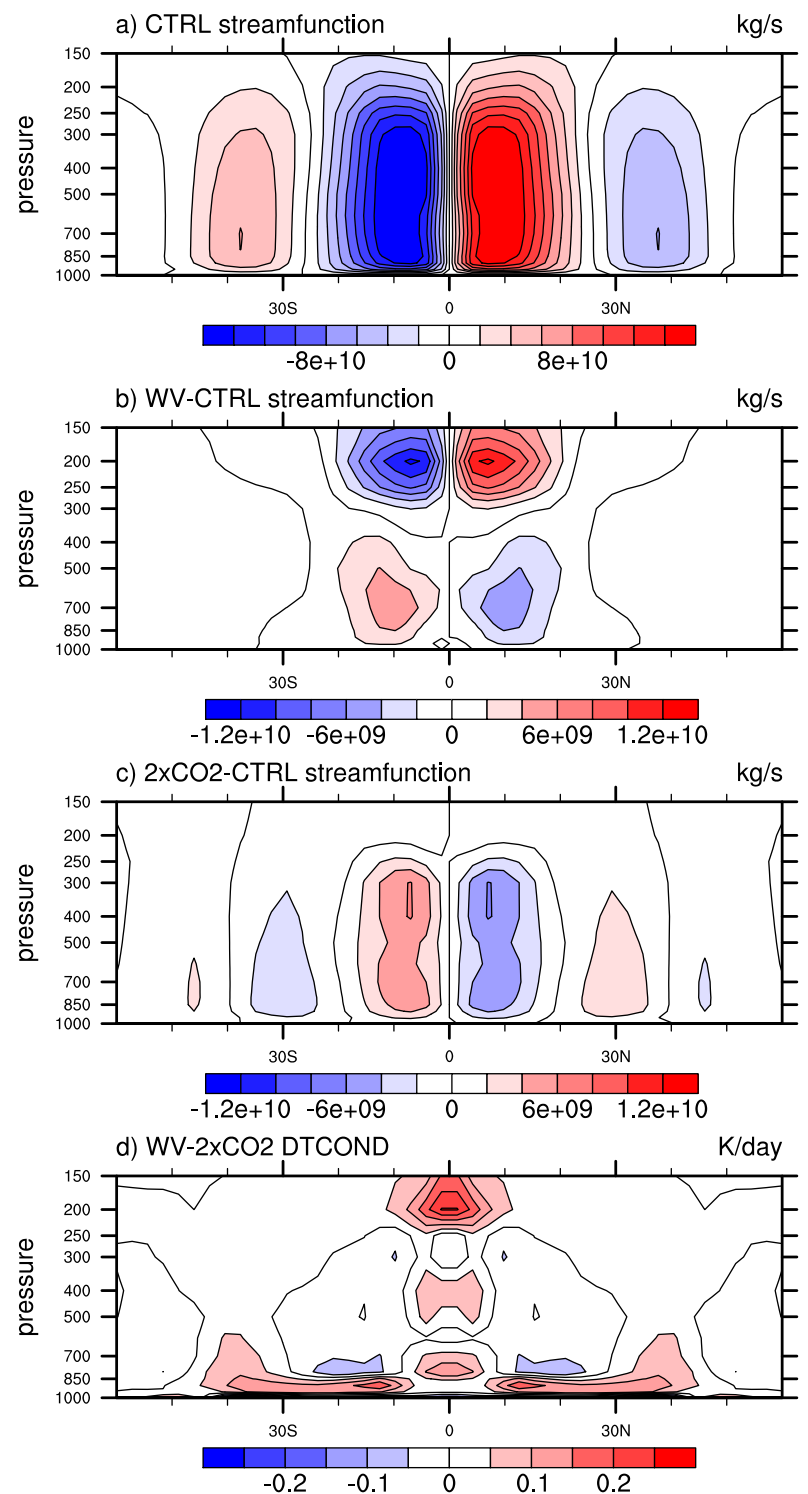

FIG. 9. (a) Zonal mean meridional mass streamfunction in the control climate (CTRL) at latitudes $-60^{\circ}$ to $60^{\circ}$. (b) and (c) Changes due to moisture (WV-CTRL) and $\mathrm{CO}_{2}$ (CO2-CTRL), respectively. (d) Zonal mean difference in heating rate due to latent heat release between the $\mathrm{WV}$ and $\mathrm{CO}_{2}$ experiments (WV-CO2). 